\title{
Monitoring of Some Organophosphorus and Organochlorine Pesticides Residue in Beef Meat from Khartoum State Slaughterhouses
}

\author{
Sara $\mathrm{AM}^{* 1}$, Afaf $\mathrm{A}^{2}$, Sahar $\mathrm{MA}^{1}$, Abubakar $\mathrm{AS}^{1}$, Abdelbagi $\mathrm{AO}^{2}$ and Abdalla $\mathrm{AM}^{2}$ \\ ${ }^{1}$ Central Veterinary Research Laboratory, Sudan \\ ${ }^{2}$ University of Khartoum \\ *Corresponding author: Sara AM, Central Veterinary Research Laboratory, Sudan.
}

To Cite This Article: Sara AM, Monitoring of Some Organophosphorus and Organochlorine Pesticides Residue in Beef Meat from Khartoum State Slaughterhouses. Am J Biomed Sci \& Res. 2019 - 6(5). AJBSR.MS.ID.001071. DOI: 10.34297/AJBSR.2019.06.001071.

Received: November 25, 2019; Published: 些 December 16, 2019

\begin{abstract}
Background: Organochlorine and Organophosphorus Pesticides are found in the environment in small concentrations, but they have cumulative characteristics thus become a threat to human health and life. This study is focused on detection and determination of some of these pesticides in bovine muscles, meat in two main slaughterhouses in Khartoum state.

Materials and methods: 50 samples were collected in sterile bags, transferred to the lab, samples were extracted within 24 hours of collection using mixture hexane and acetone, followed by partitioning and drying the samples using rotary evaporator at $40^{\circ} \mathrm{C}$. clean up step was achieved using silica gel column previously washed with hexane. Pesticides residues read against standards using GC-FID.

Results: seventy-two percentage of samples obtained from slaughterhouse one was positive, while slaughterhouse two showed $87.5 \%$ positive samples. Ethiphane is the prevailing pesticide residue in samples obtained from both slaughterhouse facilities, it represented $61.1 \%$ and $80.9 \%$ respectively. The mean value of the detected levels was 0.147 and $0.27 \mathrm{ppm}$ in order.
\end{abstract}

Keywords: Organochlorine; Organophosphorus; Meat; Ethyl Acetate; GC-FID; Methylene chloride

\section{Introduction}

Food producers must guarantee food supply by increasing production, in order to face the progress of human population development [1]. Agricultural products with its two major sectors (agricultural and animals), are at risk of encountering various debase agents such as insects, fungi, bacteria; these agents may lead to low quality products or even may cause complete loss of these products. Although, the pesticides are broadly used around the whole world since a century ago, but most of them have been debarred; especially organochlorine class affiliates. These compounds have highly toxic influence, tenacity in environment and they are characterized by their potency to accumulate in of human and animal tissues, this could be attributed to their lipophilic nature e.g. (Heptachlor) [2]. Due to the vital impact of these compounds on human health and on the environment as general, the continuous and sustainable follow up through monitor and carry on surveillances is extremely needed [3]. The common obtainability of pesticides makes the tracking of these compounds' residue in environment; particularly in food; an imperative issue [4].

These compounds have the ability to remain without being degraded in the environment, in addition to lipophilic nature and bioaccumulation tendency, all these criteria make them detectable in high concentrations in fatty foods, such as chicken, fish, meat and dairy products. The residual amounts of pesticides lead to tremendous negative effect on human health whom consume those products [5]. In order to lower the risk of consuming such products, efforts should be done to guarantee obligation with maximum residue limits in food commodities which is globally determined [6,7]. One of the pesticides classes, those intricate in toxicity is organophosphorus pesticides. The neurotoxicity caused 
by this class of pesticides is due to their capability to inhibit the acetylcholinesterase [8]. OPs may also be concentrated in fat. The degradation of the OPs and the formation of primary and secondary metabolites are induced by exposure to high temperature; light; enzymatic systems; microorganisms; and acidic, neutral, and alkaline PHs. However, in beef muscle some OPs and their metabolites could not be completely eliminated after cooking [9].

The present work is carried out to screen the occurrence of organochlorine and organophosphorus pesticides residue in meat obtained from two slaughterhouses. As well, this work is made, to determine the level of the residues and compare it with the maximum residue limits which authorized by the international organizations.

\section{Materials and Methods}

Study area: Khartoum state.

Sampling: samples were assembled from two slaughter facilities; from November 2016 to February 2017. A Total of 50 meat samples were taken into sterile bags, placed in ice and transported to the lab kept in $-20^{\circ} \mathrm{C}$. Samples were extracted within 24 hours of collection.

\section{Chemicals: All chemicals used are GC grade}

Standards: were obtained from University of Khartoum, college of agriculture, department of crops protection, samples analyzed at the central lab of shambat campus-University of Khartoum using Gas chromatograph equipped with FID.

\section{Samples Extraction}

Extraction: Meat tissue samples were extracted for O.C and O.P pesticides residue following the procedure described by [10]. Twenty grams of each meat sample, were weighed and placed in a blender with $20 \mathrm{~g}$ of sodium sulphate anhydrous and merged in a high speed then $120 \mathrm{ml}$ of $\mathrm{n}$-hexane and $120 \mathrm{ml}$ of acetone were added to the mixed sample, then the sample and the solvents were blended for 15 minutes. Distilled water is used to wash the extract in a separatory funnel. The sample wetness was dried by passing through anhydrous sodium sulphate and the solvents were dispersed at $40 \mathrm{C}$ in a rotary evaporator till complete dryness.

Partitioning: Partitioning of the extracted meat samples was performed according to Leon et al. [11].
Described procedure. $500 \mathrm{ml}$ petroleum ether was segregated with $500 \mathrm{ml}$ acetonitrile. Both two solvents were assorted in separatory funnel then separated from each other for use in sample partitioning. Sample was relocated with $25 \mathrm{ml}$ petroleum ether and $10 \mathrm{ml}$ acetonitrile into a $100 \mathrm{ml}$ separatory funnel, then $15 \mathrm{ml}$ n-hexane was added. Separatory funnel was agitated vigorously for one minute. After separation of the two solvents layers, acetonitrile was collected in a flask after passing through anhydrous sodium sulphate to remove any remained water. Additional $20 \mathrm{ml}$ of acetonitrile were added to petroleum ether in the separator funnel and the formerly mentioned steps were repeated for two times. The petroleum ether layer was casted off and acetonitrile was dispersed by rotary evaporator.

Cleanup: The samples extracts, about $(5 \mathrm{ml})$ were moved to silica gel cartridge (wet with n-hexane. The column was eluted with $200 \mathrm{ml}$ eluant $(50 \%$ methylene chloride $+1.5 \%$ acetonitrile $+48.5 \% \mathrm{n}$-hexane) at the proportion of $5 \mathrm{ml} / \mathrm{min}$. The collected eluant was concentrated on rotary evaporator at $40 \mathrm{C}$ and liquified in $2 \mathrm{ml}$ of ethyl acetate for residue analysis.

Blank Solution: Equal volume of solvents (Hexane - acetone) and sodium sulphate anhydrous; which were used in sample extraction; subjected to the similar extraction, partitioning and clean up procedures as the examined samples to distinguish any possible traces of the studied pesticides.

\section{Standardization and Validation Studies of Gas Chromatography Technique}

The system precision was assessed by reviewing the reproducibility of the instrumental reaction with respectto retention time and area of an analyte. Specificity was evaluated by graphical observation of chromatograms of blank sample matrix and sample matrix spiked with standards mixture. The standards calibration curves of the analyzed OP and OC pesticides offered a good regression line $(R 2>0.99)$ in the range of explored concentrations. The graphs showing calibration curves of these pesticides, shown that all concentrations of the OP and OC pesticides under study were collinear and thus calibration curves were further employed for the detection of analytes under study. The limit of detection (LOD) and the limit of quantitation (LOQ) were determined on the basis of noise/signal ratio (Figure $1 \&$ Table 1 ).

Table 1: Method performance parameters for detection of residues in meat for OC and OP pesticides.

\begin{tabular}{|c|c|c|c|}
\hline Pesticide & LOD $\mathbf{~ m g} / \mathbf{L}$ & LOQ $\mathbf{~ m g} / \mathbf{L}$ & $\mathbf{R}^{2}$ \\
\hline Profenofos & 0.002 & 0.0064 & 0.999 \\
\hline Malathion & 0.01 & 0.036 & 0.999 \\
\hline Diazinon & 0.001 & 0.0031 & 0.974 \\
\hline Ethiphane & 0.02 & 0.069 & 0.999 \\
\hline Oxyfloufene & 0.001 & 0.0038 & 0.999 \\
\hline Chlorpyrifos & 0.001 & 0.004 & 0.999 \\
\hline
\end{tabular}

LOD: Limit of Detection; LOQ: Limit of Quantification 


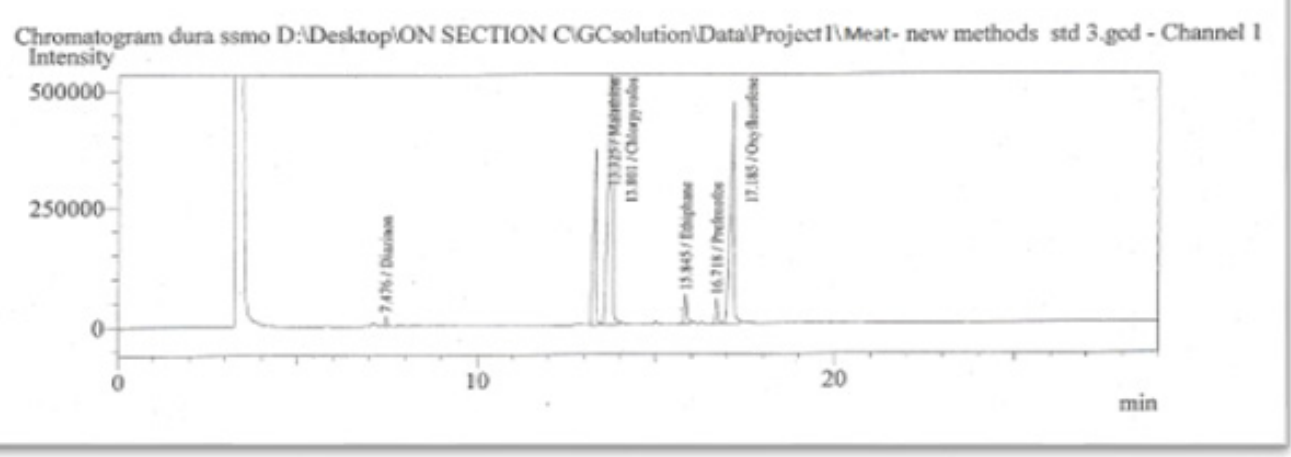

Figure 1: Elution pattern of standards mixture.

\section{GC analysis condition}

Analysis of pesticides residues was performed with a gas chromatograph system coupled with FID. DB-5 column used for analysis, with film thickness $0.25 \mu \mathrm{m}$, the total column length is $30 \mathrm{~m}$. The temperature was set at $100^{\circ} \mathrm{C}$ as initial temperature and $250^{\circ} \mathrm{C}$ as final temperature. Nitrogen was used as a carrier gas with a flow rate of $30 \mathrm{ml} / \mathrm{min}$. The injection volume was $20 \mu \mathrm{l}$; with a split injection mode. Injector was heated on $250^{\circ} \mathrm{C}$ with the following injection program for oven: $100^{\circ} \mathrm{C}$ (hold $0 \mathrm{~min}$ ), to $220^{\circ} \mathrm{C}$, $2^{\circ} \mathrm{C} / \mathrm{min}$ to $235^{\circ} \mathrm{C}$ (hold $5 \mathrm{~min}$ ), $5^{\circ} \mathrm{C} / \mathrm{min}$ to $250^{\circ} \mathrm{C}$ (hold $10 \mathrm{~min}$ ). Pesticides were identified by comparing their retention times on chromatogram with those of the standards mixture of OC and OP Pesticides.

\section{Statistical analysis}

The analysis was carried out using Statistics-10 program designed for Windows. Differences between obtained values were performed by analysis of variance (ANOVA) the LCD test was used for determining the significance level of at least $p<0.05$.

\section{Results}

Seventy-two percentage of samples obtained from slaughterhouse one $(n=25)$; were positive. $44.5 \%$ of these samples contained one pesticide residue, while $55.5 \%$ restrained more than one (Figure 2). Meantime; slaughterhouse two, showed $87.5 \%$ positive samples; $57.1 \%$ contained one pesticide residue, and in $42.9 \%$ of them contained more than one pesticide residue was detected $(n=25)$. Ethiphane is the prevailing pesticide residue in samples obtained from both slaughterhouse facilities, it represented $61.1 \%$ and $80.9 \%$ respectively. The mean value of the detected levels was 0.147 and $0.27 \mathrm{ppm}$ in order. Regarding slaughter facility number (1), the second dominant detected pesticide residue was profenofos; with percentage $44.4 \%$, mean value $0.079 \mathrm{ppm}$. Oxyfluorfen come in the third position, with $27.8 \%$ positive samples and mean value $0.026 \mathrm{ppm}$. while; slaughterhouse two results were as follows, Ethiphane, followed by Oxyfluorfen $33.3 \%$, mean value $0.0008 \mathrm{ppm}$ and malathion occupied the third place $14.3 \%$, mean value $0.01 \mathrm{ppm}$.

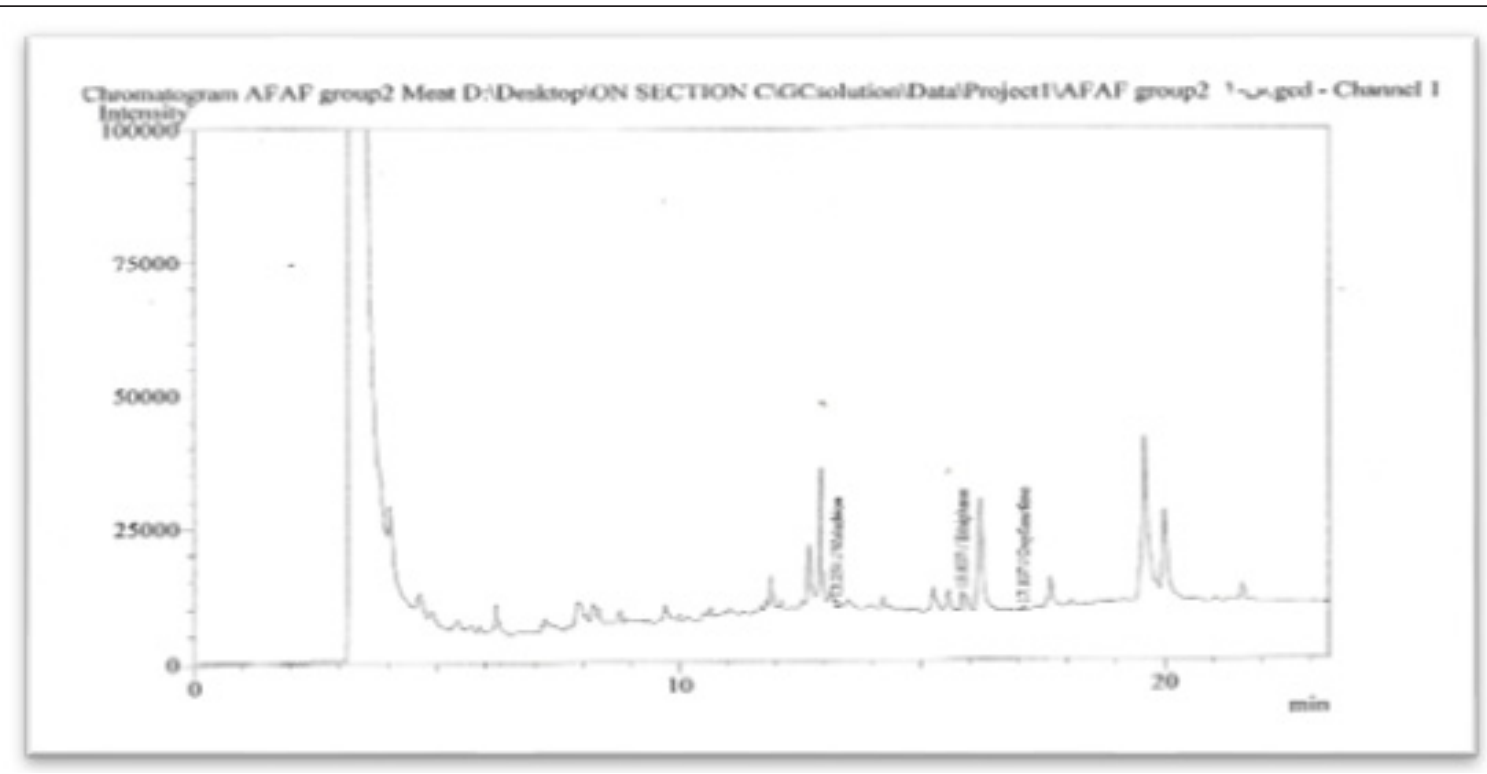

Figure 2: Elution pattern of organophosphorus pesticide residue in meat sample from slaughterhouse (1). 
In consideration to slaughterhouse (1); $33.3 \%$ of samples which contained diazinon residue exceeded the maximum residue limits; which defined by the specialized organizations. As well as, $37.5 \%$ of samples contained profenofose. Samples which contained Ethiphane and Oxyfluorfene, the residue in all samples, was over the allowed levels. The same trend was followed in slaughterhouse (2), all oxyfluorfene and ethiphane residue limits exceeded the permissible levels. Diazinon and profenofos levels; were below the acceptable limits (Figure $3 \&$ Table 2).

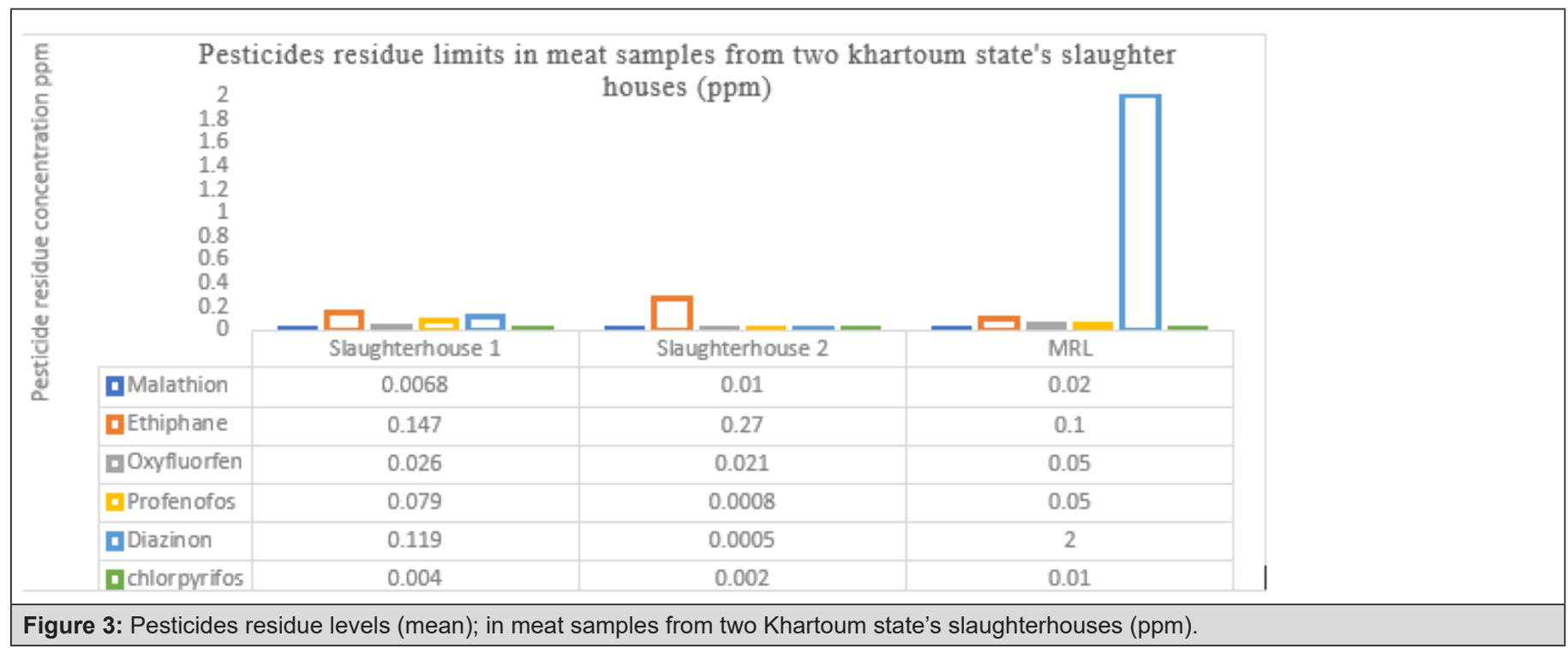

\begin{tabular}{|c|c|c|c|c|c|c|c|}
\hline \multirow{2}{*}{ Pesticide } & \multirow{2}{*}{$\begin{array}{l}\text { Min } \\
\text { ppm }\end{array}$} & \multirow{2}{*}{$\begin{array}{l}\text { Max } \\
\text { ppm }\end{array}$} & \multirow{2}{*}{ Mean \pm SE } & \multirow{2}{*}{$\begin{array}{l}\text { MRL } \\
\text { ppm }\end{array}$} & \multicolumn{2}{|c|}{ Incidence (+) } & \multirow{2}{*}{ Class } \\
\hline & & & & & No & $\%$ & \\
\hline Profenofos & 0.02 & 1.66 & $0.04007 \pm 0.01$ & 0.05 & 10 & 20 & OP Insecticide \\
\hline Malathion & 0.07 & 0.1 & $0.00843 \pm 0.015$ & 0.02 & 5 & 10 & OP Insecticide \\
\hline Diazinon & 0.012 & 2.4 & $0.0601 \pm 0.0024$ & 2 & 3 & 6 & OP Insecticide \\
\hline Ethiphane & 0.2 & 2.36 & $0.2086 \pm 0.46$ & 0.1 & 24 & 48 & $\mathrm{OP}$ \\
\hline Oxyfloufene & 0.06 & 0.4 & $0.0236 \pm 0.03$ & 0.05 & 11 & 22 & OC Herbicide \\
\hline Chlorpyrifos & 0.05 & 0.056 & $0.032 \pm 0.012$ & 0.01 & 4 & 8 & OP Insecticide \\
\hline
\end{tabular}

\section{Discussion}

The contamination of animal's products, which proposed for human consumption can occur via different approaches. The animal which exposed to pesticides in order to control insects; by dipping or spraying and due to the fat solubility nature of these chemicals, animals have tendency to accumulate and store them in their bodies. The total withdrawing process of these chemicals from the animal's body may take 3-4 months. Some of these materials, has vital consequences on both animal and human, while others have little pronounced effect. Animal products proposed for food may become contaminated with pesticide chemicals in a number of ways. Some of the pesticides used in spraying and dipping cattle, sheep, goats, and swine are stored in the animals' bodies. Some materials have caused serious disturbances and even fatalities. Others have little apparent effect. Most of the pesticides used for insect control are soluble in the fat and are stored in the fatty tissues of the animal. Three to four months are required before some of the chemicals are entirely eliminated.
Remarkably; most of the detected pesticides belongs to Organophosphate group. Profenofos, Diazinon, Malathion and Ethiphane, while the only detected organochlorine pesticide was Oxyfluofene.

\section{Different approaches could be incorporated in pesticides reach to the animal}

Wastewater of irrigation after spraying the crops, Animal feedstuff that were poisoned throughout the pesticide's application process, or via Air that was polluted with pesticides during spraying. Oxyflourfene and Ethiphane positive samples were all above the (MRL), for Ethiphane; its presence in soil and potency to accumulate in plants. Walla allden \& Azhary [12] reported high concentrations of Malathion, Oxyfluorfene, Ethiphane and Profenofos residue contamination in agricultural crops cultivated in El-Gash soil. Taking in concern the possibility of pesticide diffusion in soil, and leakage into underground water in addition to accumulation in different cultivated crops, makes finding of these pesticides residue in cattle meat is reasonable, since the pesticides 
could be administrated to the animal throw different roots. Three samples out of 50 were Diazinon positive, one of them exceeded the (MRL), this finding is not in accordance with the results of [13], who did not detect Diazinon residue in cattle beef of animals locally raised in Egypt.

But our result was in line with report of Ahmed et al. [13], they reported Diazinon residue in muscles and livers of all camel, sheep and cattle carcasses, which were inspected. The residue was above the acceptable limits in cattle and camel carcasses. Profenofos was also detected in sheep and cattle tissues; but the detected levels were below the (MRL), this result could be attributed to the massive use of Diazinon to control ticks in farms. Roberts and his colleague reported Malathion residue in tissues of sheep and goats. The detected residue was under the acceptable except for the residue obtained from omental fats of goats, which was above the acceptable level $3.2 \mathrm{ppm}$, [14]. Bindu et al. [15] mentioned that, they have detected Malation and chlorpyrifos residue in pork and chicken meat samples; randomly collected from markets in Pakistan. Dallegrave \& his coworkers [16], detected chlorpyrifos residue in meat, fish and egg samples, but none of those of detected residue was beyond the acceptable limit, this result disagrees with the current findings. Another study; held in Faisalabad to compare the residue of chlorpyrifos and other pesticides in meat samples; they verified chlorpyrifos residue in meat samples, the detected amount was higher than the documented levels in literature $[17,18]$, this result synergize our present findings.

\section{Conclusion}

The detected pesticides residue in the present study, may reveal the wide, intensive use of organophosphorus pesticides in Sudan in comparison with organochlorines. Out of 6 detected pesticides 5 were belong to organophosphate class. Ethiphane is the prevailing pesticide residue in samples obtained from both slaughter facilities. All samples in which Ethiphane and Oxyfluorfene were detected, the residue was over the allowed levels.

\section{Recommendations}

The presence of herbicides residue in meat samples in the current study, had demonstrated the transfer of pesticides through linear chain from soil to underground water, plants and consumption by the animals leading to accumulation of residues in their products. The hazard of human consumption of animal products polluted with pesticides residue make it necessary to upraise the awareness of producers and consumers with standard pesticides usage, with stress on committing to withdrawal period of every and each pesticide.

\section{References}

1. Mohammadreza Rezaeigolestani and, Mohammad Hashemi (2018) A Review of Pesticide Residues in Agricultural and Food Products of Iran. J Fasting Health 6(1): 1-6.
2. Doyle J (2004) Trespass against us: DOW chemical \& the toxic Century, Canada.

3. Voldner C Eva, Yi-Fan Li (1995) Global usage of selected persistent organochlorines. Science of the Total Environment 160-161: 201-210.

4. Lebel G, S Dodin, P Ayotte, S Marcoux, L Ferron, et al. (1998) Organochlorine exposure and the risk of endometriosis. Fertility and Sterility 69(2): 221-228.

5. Ahmed M Aboul-Enein, IN Nasr, Faten M Abou Elella, Emad S Abdullah (2010) Monitoring of some Organochlorines and Organophosphorus residues in imported and locally raised chicken and bovine muscles in Egypt. Journal of Applied Sciences Research, 6(6): 600-608.

6. Jae-Woo Parka, AM Abd El-Atya, Myoung-Heon Leeb, Sung-Ok Songb, Jae-Han Shima (2006) Residue Analysis of Organophosphorus and Organochlorine Pesticides in Fatty Matrices by Gas Chromatography Coupled with Electron-Capture Detection. in Zeitschrift fur Naturforschung C. PubMed.

7. Codex (2006) Maximum residue limits for pesticide residues in food.

8. Klaassen CD (1996) Nonmetallic Environmental Toxicants: Air Pollutants, Solvents and Pesticides". In Goodman and Gilman's, The Pharmacological Basis of Therapeutics, International Edition. JG Hardman, LE Limbird, PB Molinoff, RW Ruddon and A Goodman-Gilman, Eds. McGraw-Hill, New York, 1673-1696.

9. Coulibaly K, Smith JS (1994) Effect of pH and cooking temperature on the stability of organophosphate pesticides in beef muscle. J. Agric. Food Chem. 42: 2035-2039.

10. Abd El-Kader, MA (1989) Pesticide residues in chicken tissues and its public health importance. Egypt J Appl Science 4: 59-64.

11. Leon DS, Bernardett MM, Newsome WH, Gail AP (1990) Association of Official Analytical Chemistry; pesticide and industrial chemical residues, USA 274-291.

12. Walla Alden Ibrahim Abdalfadil, Azhari Omer Abdelbagi (2019) Soil Residue level of the commonly used pesticides at AL-Gash River in area of kassala state. University of Bakht Alruda, refereed by quarterly scientific journal (23): 58-64.

13. Ahmed MA Meligy, Abdallah Y Al-Taher, Mohamed Ismail, Abdelmohsen A Al-Naeem, Sabry M El-Bahr, et al. (2019) Pesticides and toxic metals residue in muscle and liver Tissues of sheep, cattle and dromedary camel in saudi arabia. Slov Vet Res; 56 (22): 157-166.

14. Roberts RH, Radeleff RD, Wheeler HG (1960) Malathion residue in the tissues of sheep, goats and hogs. Journal of Economic Entomology 53(5): 972-973.

15. Bindu Ch, Kiranmayi, Krishnaiah N, Muthu Kumar M, Subhashini N., et al. (2018) Detection of organochlorine, organophosphorus and synthetic pyrethroid residues in pork, chicken, fish and fish pond water samples. The Pharma Innovation Journal 7(12): 13-16.

16. Dallegrave A, Pizzolato TM, Barreto F, Bica VC, Eljarrat E, et al. (2018) Residue of insecticides in foodstuff and dietary exposure assessment of Brazilian citizens. Food Chem Toxicol (115): 329-335.

17. Muhammad F, Akhtar M, Rahman ZU, Farooq HU, Khaliq et al. (2010) Multi-residue determination of pesticides in the meat of cattle in Faisalabad-Pakistan. Egypt Acad J biolog Sci 2 (2): 19-28.

18. Sultatos LG (1994) Mammalian toxicology of organophosphorus pesticides. J Toxicol Environ Health 43: 271-89. 